\title{
Minimum intervention management of diastema closure using cordless displacement system and laminate veneers: A 2-year follow-up
}

\author{
Ana Teresa Maluly-Proni ${ }^{1}$, Bruna Oliveira-Reis ${ }^{2}$, Wirley Gonçalves Assunção ${ }^{1}$, \\ Paulo Henrique Dos Santos ${ }^{1}$
}

Correspondence: Dr. Paulo Henrique Dos Santos Email: paulosantos@foa.unesp.br

\begin{abstract}
'Department of Dental Materials and Prosthodontics, Araçatuba School of Dentistry, São Paulo State University - UNESP, São Paulo, Brazil,

2Department of Restorative Dentistry, Araçatuba School of Dentistry, São Paulo State University - UNESP, São Paulo, Brazil
\end{abstract}

\begin{abstract}
This case report presents a minimally invasive diastema treatment using cordless gingival displacement system allowing a very conservative intervention. A 32-year-old female patient who presented with diastema in her upper front teeth opted for a treatment using laminate veneers to ensure achieving adequate tooth proportion and gingival levels. Having a displacement material that exerts excessive pressure during the displacement process can lead to disruption of the junctional epithelium and damage to periodontal tissues. This case report focuses on the effectiveness of the use of a minimally invasive method of gingival management. Two-year follow-up no infiltration, sensitivities, or fractures were detected on teeth, and indirect restorations, the purposed treatment allowed a quick, effective, and durable resolution for diastema.
\end{abstract}

Key words: Esthetics, dental veneers, diastema, gingival retraction techniques

\section{INTRODUCTION}

The presence of diastemas is a common patient complaint that may affect self-esteem, leading patients to seek esthetic treatment. Originating from differences in tooth size, a maxillary midline diastema is a space $>0.5 \mathrm{~mm}$ between the proximal surfaces of the two central incisors. ${ }^{[1,2]}$ This space can be a normal growth characteristic, and it is usually closed by the time, the maxillary canines erupt; however, it has a prevalence in adults ranging from $1.6 \%$ to $25.4 \% .{ }^{[3]}$

Among several possible treatments available, one of the preferred options for esthetic treatment of

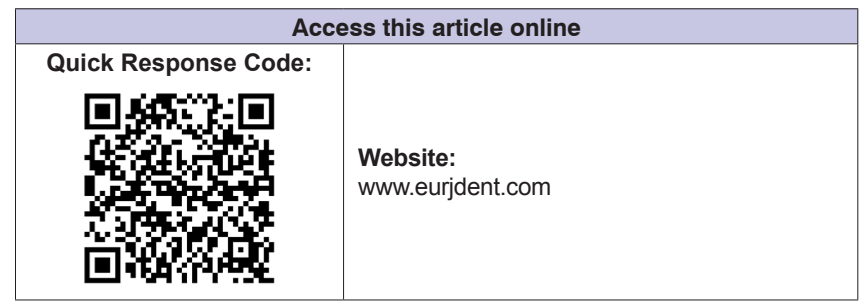

a diastema ${ }^{[1]}$ is laminate veneers due to esthetic resolution, color stability, mechanical properties, and biocompatibility, ${ }^{[4]}$ which may be indicated when there is appropriate remaining sound dental structure. ${ }^{[5]}$

When dealing with ceramic restorations, an accurate marginal adaptation is required to ensure long-term clinical success. ${ }^{[6]}$ Thus, many gingival retraction techniques (conventional and cordless) and products (mainly astringents and vasoconstrictors) are available. ${ }^{[6]}$ Astringents based on aluminum

This is an open access journal, and articles are distributed under the terms of the Creative Commons Attribution-NonCommercial-ShareAlike 4.0 License, which allows others to remix, tweak, and build upon the work non-commercially, as long as appropriate credit is given and the new creations are licensed under the identical terms.

For reprints contact: reprints@medknow.com

How to cite this article: Maluly-Proni AT, Oliveira-Reis B, Assunção WG, Dos Santos PH. Minimum intervention management of diastema closure using cordless displacement system and laminate veneers: A 2-year follow-up. Eur J Dent 2018;12:446-9.

DOI: 10.4103/ejd.ejd_208_18 
chloride products are used most widely due to the chemical's only local action, ${ }^{[7]}$ and were introduced as an alternative to cord methods and may also be used with displacement cord..$^{[6,8]}$

The astringent retraction paste was developed to enhance gingival displacement and assist hemostasis, but its effectiveness has not been well documented in clinical longevity. Based on that, the proposed case report described here aims to demonstrate a conservative solution for the treatment of diastema using a cordless displacement method.

\section{CASE REPORT}

A 32-year-old female patient presented with complaints of spacing in her upper front teeth and the desire to have her teeth esthetically corrected [Figure 1a]. After obtained a patient consent form, all the routine investigations, such as radiographic, clinical examination, and dental history, were within normal limits, and there was no relevant history contributory to the diastema. On intraoral examination, the patient presented a midline diastema of $1.5 \mathrm{~mm}$ and sound periodontal conditions.

Treatment options given to the patient were closure of the space by laminate veneers and orthodontic closure of the space. The patient opted for laminate veneers given the shorter duration of treatment. Digital planning of the smile was performed to facilitate the explanation. After getting informed consent, the treatment protocols were started.

The diagnostic impressions were taken using addition silicone impression material Express XT Putty and Light Body (3M ESPE, St Paul, MN, USA), poured with a Type IV dental stone Kromotypo4 (Lascod, Sesto Fiorentino, Florence, Italy). One study model was used for a wax-up of the central and lateral incisors. On another study model, mock preparations were done in relation to dental elements 11, 12, 21, and 22. Before continuing to tooth preparation, the color shade was selected using a Vitapan Classical shade guide (Vita Zahnfabrik, Bad Säckingen, Germany).

The veneer preparations started with mock-up placement. Margins were established using a long, tapered, and medium-grit diamond, and tooth contacts were removed. The preparation design needed to permit a thickness of $0.4 \mathrm{~mm}$ at the gingival margin, $0.6 \mathrm{~mm}$ in the midbody, and 0.6 in the incisal third to prevent dentin shine through and to conceal the margins of the preparation under the porcelain. The incisal ed ges were reduced $1 \mathrm{~mm}, 30^{\circ}$ toward lingual surfaces in relation to 11 and 21, with a slight lingual wrap, and avoiding centric contacts [Figure 1b].

Gingival management was performed using the astringent retraction paste (3M ESPE, St Paul, MN, USA), that was placed into the sulcus presented by a continuous line around the circumference of the teeth, and allowed to sit for 2 min [Figure 1c]. To wash the paste from the sulcus, water spray was used, followed by air-drying. The hemostatic property of the paste left the prepared tooth fully dry. Margins were inspected, and then, a final impression was taken using a one-step addition silicon technique Express XT and Light Body Paste (3M ESPE) and sent to the laboratory [Figure 1d]. Provisional restorations were done using Protemp ${ }^{\mathrm{TM}} 4$ Temporization Material (3M ESPE, Seefeld, Germany).
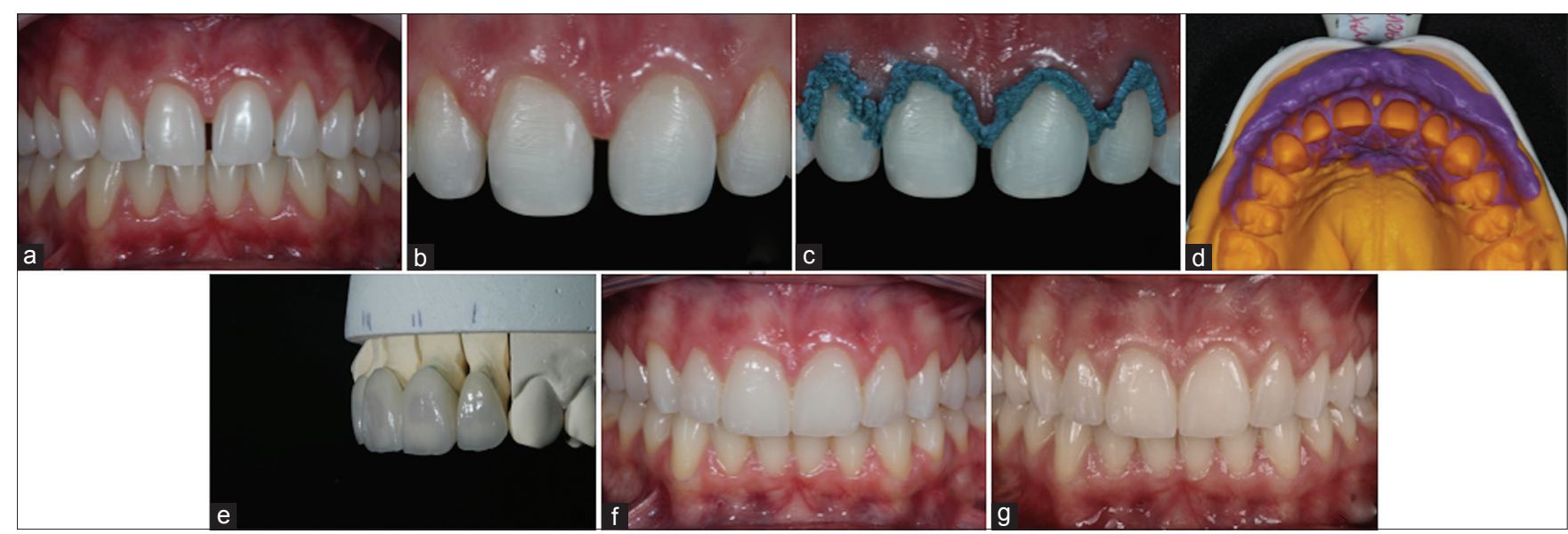

Figure 1: Photographs of the case (a) initial view; (b) completed teeth preparation; (c) gingival management with astringent retraction paste; (d) addition silicone impression; (e) laminate veneers; (f) final case; and (g) 2-year follow-up 
In the laboratory, pressable lithium disilicate glass-ceramic was used IPS e.max Press BL4 HT (Ivoclar Vivadent, Schaan, Liechtenstein) for the fabrication of the veneers [Figure 1e]. Before cementation, the interior surfaces of the laminates were etched with $10 \%$ hydrofluoric acid (FGM, Joinville, SC, BR) for $20 \mathrm{~s}$ and silanized with a silane coupling agent (Angelus, Londrina, PR, Brasil). The teeth were cleaned with a slurry of pumice, and gingival displacement was acquired using a \#000 retraction cord (Ultradent Products, Inc., South Jordan, USA). Acid etching was done with 35\% phosphoric acid Ultra-Etch (Ultradent Products Inc., South Jordan, USA) and rinsed off after $15 \mathrm{~s}$, following the manufacturer's recommendations. All the teeth surfaces were coated with a bonding agent Adper Single Bond 2 (3M ESPE, St Paul, MN, USA) in a thin layer and light polymerized for 20 s. A light-cured composite luting agent RelyX Veneer (3M ESPE, St Paul, MN, USA) of translucent shade was selected and placed on the internal surface of the veneers. With luting cement, the laminates were gently seated with finger pressure on the teeth, checking the margins. Excess cement was removed with a soft brush. Light polymerization was performed with a light-emitting diode curing unit valo (Ultradent Products, Inc., South Jordan, USA) on standard power for $40 \mathrm{~s}$ from buccal, incisal, mesial, and distal aspects of each tooth. To remove major excesses, a \#12 blade was used. Restorations were checked for any occlusal interference. There was a significant and satisfactory improvement in the overall appearance of the patient regarding esthetics [Figure 1f].

The patient was motivated to perform good oral hygiene and to attend the reviews. Two-year follow-up no infiltrations, sensitivities, or fractures were detected on the teeth and the indirect restorations [Figure 1g].

\section{DISCUSSION}

A diastema, or maxillary anterior spacing, is an esthetic problem that presents a higher prevalence in the maxilla than in the mandible and has a multifactorial etiology $\cdot^{[1,2]}$ In addition to microdontia, lateral incisor agenesis, cysts in the midline region, habits such as finger sucking, and genetics can cause diastemas. ${ }^{[9]}$ Several treatment modalities include orthodontic appliances. Even though this was a viable option, ${ }^{[1]}$ the patient in the present case report did not want to spend time with many appointments.

What usually determines the treatment plan for esthetic rehabilitation of a midline diastema is the width-to-length ratio of the central incisors. The amount of distal proximal reduction, how many teeth will be treated, and the placement of full veneers or not are all decisions made according to that ratio. ${ }^{[10]}$ Restorative and prosthodontic solutions are most amenable to treat diastemas based on tooth-size discrepancy. ${ }^{[1]}$ Composite resin is easy to use, requires fewer appointments, and is economic but offers less wear resistance and surface staining, which makes it inferior to dental porcelain. ${ }^{[1]}$ Besides that, smiles can be painlessly, conservatively, and quickly transformed with the use of porcelain laminate veneers; tissue response is great, and the finished surface is very similar to the natural tooth. ${ }^{[1]}$

Especially in prosthodontic solutions, achieving excellent marginal adaptation requires excellent impression quality, and it is crucial to the success of the restoration. Factors such as quality of preparation, chosen technique, and soft-tissue management can affect the accuracy of the definitive impression. ${ }^{[11]}$ It is known that applying excessive pressure during the displacement process may lead to high levels of disruption of the junctional epithelium. ${ }^{[12]}$ The placing cord method has been shown to generate pressures $>5000 \mathrm{kPa},{ }^{[8]}$ which is partly due to technique sensitivity and the influence of the physical pressure applied by the clinician. This pressure value is higher when compared to the cordless method (about $100 \mathrm{kPa}$ ), indicating greater effectiveness. ${ }^{[8]}$ However, cordless gingival displacement materials remove the need for physical packing of the material into the crevicular sulcus, thereby reducing periodontal damage, bleeding, and healing time. ${ }^{[8]}$

In this case report, a midline diastema closure treatment was carried out by minimum intervention management using a cordless displacement system and laminate veneers, contrasting with the use of conventional displacement cords, which are a common method for this kind of case. ${ }^{[1,4]}$

Having a displacement material that is quick to place and activates rapidly is paramount in tissue displacement, because it reduces clinical treatment time, patient discomfort, and the risk of tissue injuries. ${ }^{[8]}$ Studies present that the retraction pastes were found to be better than cords when assessed histologically, respecting the periodontium, ${ }^{[12]}$ and did not induce bleeding during or after retraction. ${ }^{[13]}$

Ease of application is also an important factor to consider. Materials that are difficult to use can lead to 
repeated applications, causing stress for the clinician, loss of patient confidence, and increased strain on the gingival tissues. Fewer pressure variations during the injection of the material can translate into easier placement in a clinical situation. ${ }^{[8]}$ Bennani et al. showed that 3M ESPE astringent retraction paste had a minimum postinjection pressure generated on tissues compared to different cordless gingival displacement materials. However, it was not clear about their clinical effectiveness when such low pressure is exerted. Another factor to be considered is the complete removal of the astringent paste; its presence may have a negative influence on the bond strength of luting agents. ${ }^{[14]}$

This case report focused on the effectiveness of gingival displacement and the success of the use of porcelain laminate veneers, presenting positive results. Taking into consideration these positive results, an experienced dentist with proper case selection, using an appropriate technique and modern materials, can perform highly esthetic and durable treatment of diastemas that can satisfy patients under the same conditions.

Anterior ceramic laminate veneers of minimum thickness may be a conservative and esthetic option to reestablish the form and shape of anterior teeth with a diastema, and the use of a displacement paste technique is easy and efficient for marginal gingiva management.

\section{Declaration of patient consent}

The authors certify that they have obtained all appropriate patient consent forms. In the form the patient(s) has/have given his/her/their consent for his/her/their images and other clinical information to be reported in the journal. The patients understand that their names and initials will not be published and due efforts will be made to conceal their identity, but anonymity cannot be guaranteed.

\section{Financial support and sponsorship \\ Nil.}

\section{Conflicts of interest}

There are no conflicts of interest.

\section{REFERENCES}

1. Viswambaran M, Londhe SM, Kumar V. Conservative and esthetic management of diastema closure using porcelain laminate veneers. Med J Armed Forces India 2015;71:S581-5.

2. Keene HJ. Distribution of diastemas in the dentition of man. Am J Phys Anthropol 1963;21:437-41.

3. Gkantidis N, Kolokitha OE, Topouzelis N. Management of maxillary midline diastema with emphasis on etiology. J Clin Pediatr Dent 2008;32:265-72.

4. da Cunha LF, Reis R, Santana L, Romanini JC, Carvalho RM, Furuse AY, et al. Ceramic veneers with minimum preparation. Eur J Dent 2013;7:492-6.

5. da Cunha LF, Pedroche LO, Gonzaga CC, Furuse AY. Esthetic, occlusal, and periodontal rehabilitation of anterior teeth with minimum thickness porcelain laminate veneers. J Prosthet Dent 2014;112:1315-8.

6. Acar Ö, Erkut S, Özçelik TB, Ozdemır E, Akçil M. A clinical comparison of cordless and conventional displacement systems regarding clinical performance and impression quality. J Prosthet Dent 2014;111:388-94.

7. Valderhaug J, Birkeland JM. Periodontal conditions in patients 5 years following insertion of fixed prostheses. Pocket depth and loss of attachment. J Oral Rehabil 1976;3:237-43.

8. Bennani V, Inger M, Aarts JM. Comparison of pressure generated by Cordless gingival displacement materials. J Prosthet Dent 2014;112:163-7.

9. Weber FN. Orthodontic Principles and Practice. Graber TM, $3^{\text {rd }}$ ed. W.B. Saunders Company, Philadelphia. 1972.

10. Blitz N. Direct bonding in diastema closure - High drama, immediate resolution. Oral Health 1996;86:23-6.

11. Faria AC, Rodrigues RC, Macedo AP, Mattos Mda G, Ribeiro RF. Accuracy of stone casts obtained by different impression materials. Braz Oral Res 2008;22:293-8.

12. Phatale S, Marawar PP, Byakod G, Lagdive SB, Kalburge JV. Effect of retraction materials on gingival health: A histopathological study. J Indian Soc Periodontol 2010;14:35-9.

13. Al Hamad KQ, Azar WZ, Alwaeli HA, Said KN. A clinical study on the effects of cordless and conventional retraction techniques on the gingival and periodontal health. J Clin Periodontol 2008;35:1053-8.

14. O'Keefe KL, Pinzon LM, Rivera B, Powers JM. Bond strength of composite to astringent-contaminated dentin using self-etching adhesives. Am J Dent 2005;18:168-72. 